\title{
Automatic control system based on IoT data identification
}

\author{
Hankil Kim ${ }^{1}$, Jaehyun Park², Hoekyung Jung ${ }^{3}$ \\ ${ }^{1}$ Department of Music \& Sound Technology, Korea University of Media Arts, South Korea \\ ${ }^{2,3}$ Department of Computer Engineering, Paichai University, South Korea
}

\begin{tabular}{l}
\hline \hline Article Info \\
\hline Article history: \\
Received Feb 10, 2020 \\
Revised Mar 1, 2020 \\
Accepted Apr 10, 2020 \\
\hline
\end{tabular}

Keywords:

Automatic control

IoT

Priority

Sensor

Task management

\begin{abstract}
Recently, as the Internet of Things (IoT) technology has developed, researches are rigorously conducted to construct smart environments such as smart home, smart grid, and industrial IoT. However, currently existing systems consists of a series of events, and even if an existing task is running, unnecessary work still occurs as both works happen simultaneously. In this paper, we propose an automatic work control system to solve this problem. The proposed system transmits the data measured by the sensor to the server and identifies non - real - time tasks such as real - time work which is related to the dangerous situations, ventilation and temperature control. In addition, priority among the tasks is set in a way that existing tasks are stopped when high priority tasks occur. Accordingly, this can reduce the unnecessary waste of power, and the user is able to receive a proactive service.
\end{abstract}

Copyright $@ 2020$ Institute of Advanced Engineering and Science. All rights reserved.

\section{Corresponding Author:}

Hoekyung Jung,

Department of Computer Engineering,

Paichai University,

155-40 Baejae-ro, Seo-gu, Daejeon, South Korea.

Email: hkjung@pcu.ac.kr

\section{INTRODUCTION}

Currently, IoT is evolving into an intelligent system that connects networks to objects and helps people to communicate with each other [1-3]. This provides intelligent services to products or users as the system provides convenience [4]. To provide intelligent IoT services, it is essential to use sensors that collect data instead of human senses [5-7]. Accordingly, the amount of data generated between objects is increasing exponentially [8-10]. Conventional IoT system uses a batch processing method that loads measured data through a sensor into a database, extracts the loaded data from the database through a server when the user requests it, and provides the data to the user [11-13]. This batch processing method treats the sensor data generated in real time as a batch process, so it is difficult to process it in case of a dangerous situation that occurs suddenly or a job that should be executed prior to the current operation [14-16].

In this paper, we propose a system that automatically manages Tasks by identifying data of various sensors installed for environment and crime prevention management [17]. In this system, the sensor is attached to Arduino, and the threshold value is applied to each sensor [18, 19]. In addition, by setting the priority among jobs, even though a job is currently operating, if a high priority job occurs, the existing job is automatically stopped [20]. Automatic control is divided into date and time by web data extraction [21]. It is operated by environmental control at the time of use and by crime prevention control at the time of the recess [22, 23]. Also, the system provides a notification to the administrator in case of a risk such as a fire or an intrusion. Remote control is implemented to operate at the highest priority except when a dangerous situation like fire or intrusion happens [24-27].

\section{SYSTEM DESIGN}

The purpose of this system is to identify the sensor data, set the priority among the tasks, and operate automatically according to the date and time through web data. The proposed automatic control 
system transmits the measured sensor data to the server, processes the event through the threshold value, and monitors the status of the management place with the application. In addition, administrators can remotely control devices, and a notification message is provided in case of a dangerous situation. Figure 1 shows the configuration of the proposed Task automatic control system. The measured sensor data is transmitted to the server in real time, and the task priority is automatically set according to the environment. Figure 2 shows the Architecture of the Tasks automatic control system.
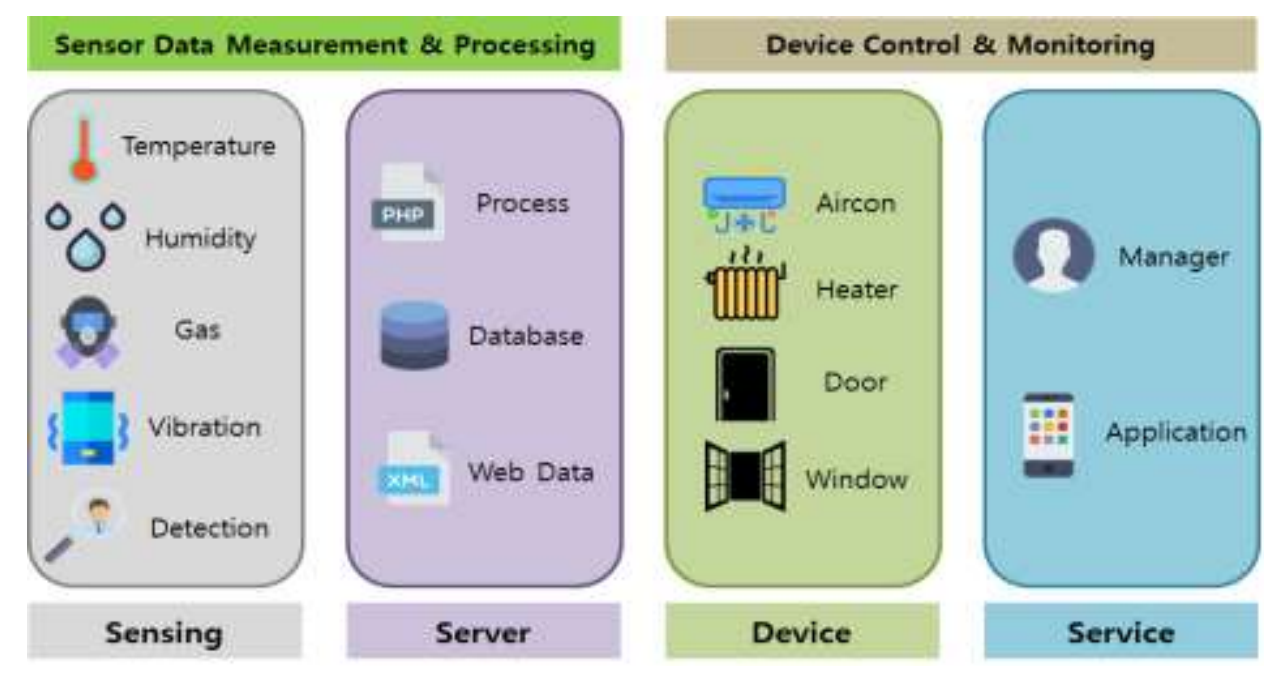

Figure 1. Tasks automatic control system block diagram

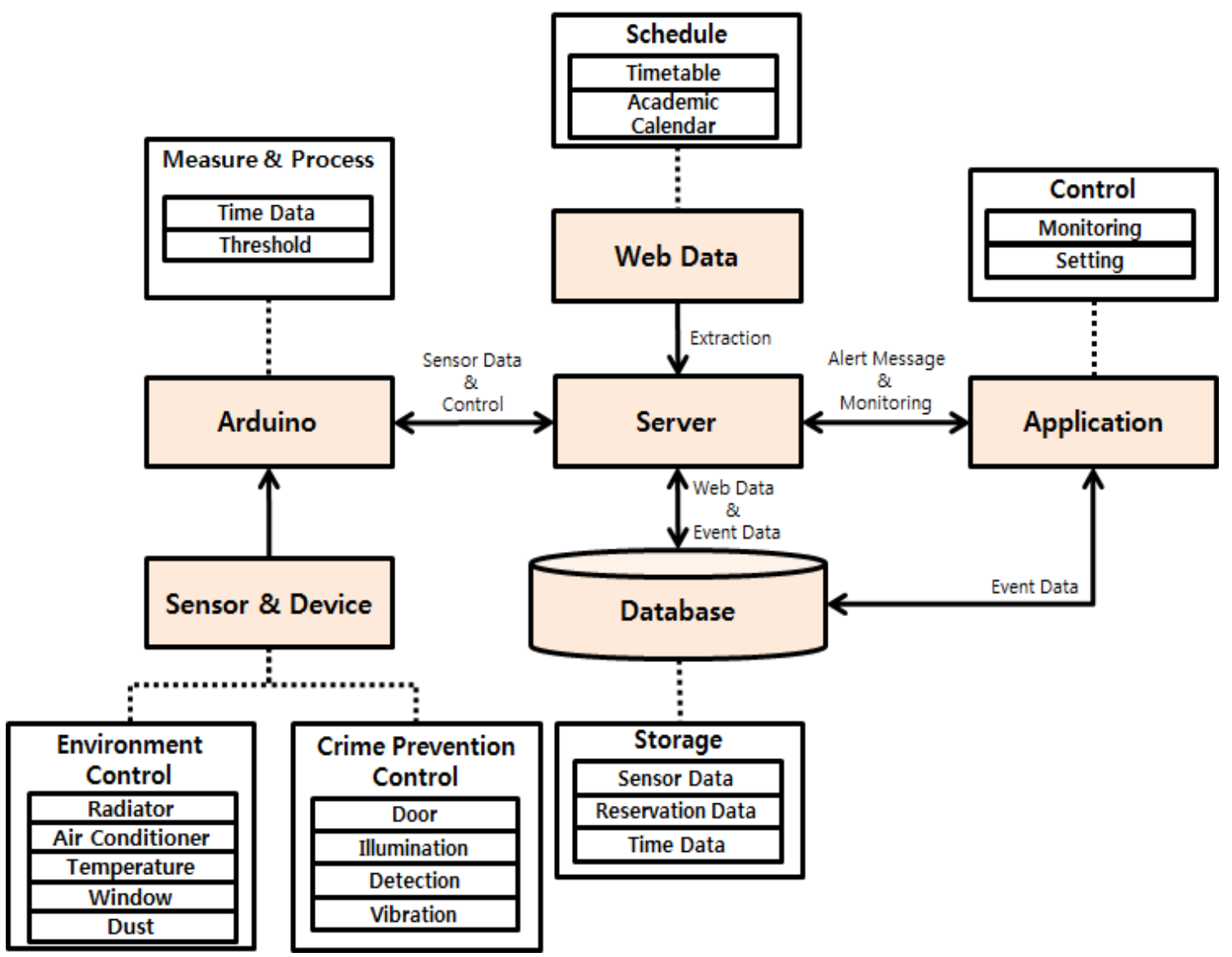

Figure 2. Tasks automatic control system block diagram.tasks automatic control system architecture 
Sensors and devices are classified into environment control and security control devices, and each sensor data is transmitted to the server through Arduino. The server determines whether the management place is in use by extracting sensor data and web data, operates the device, and then loads the current state into the database. In addition, priority is assigned to the tasks to be provided to the device in order. The database contains sensor data measured in real time, device status, web data for distinguishing use date and time, membership information for identifying an administrator, and tokens of an administrator for transmitting a notification message in a dangerous situation. In an application, an administrator can monitor the current status of a management place and remotely control the device if necessary. Figure 3 is a flow chart of sensor data identification algorithm.

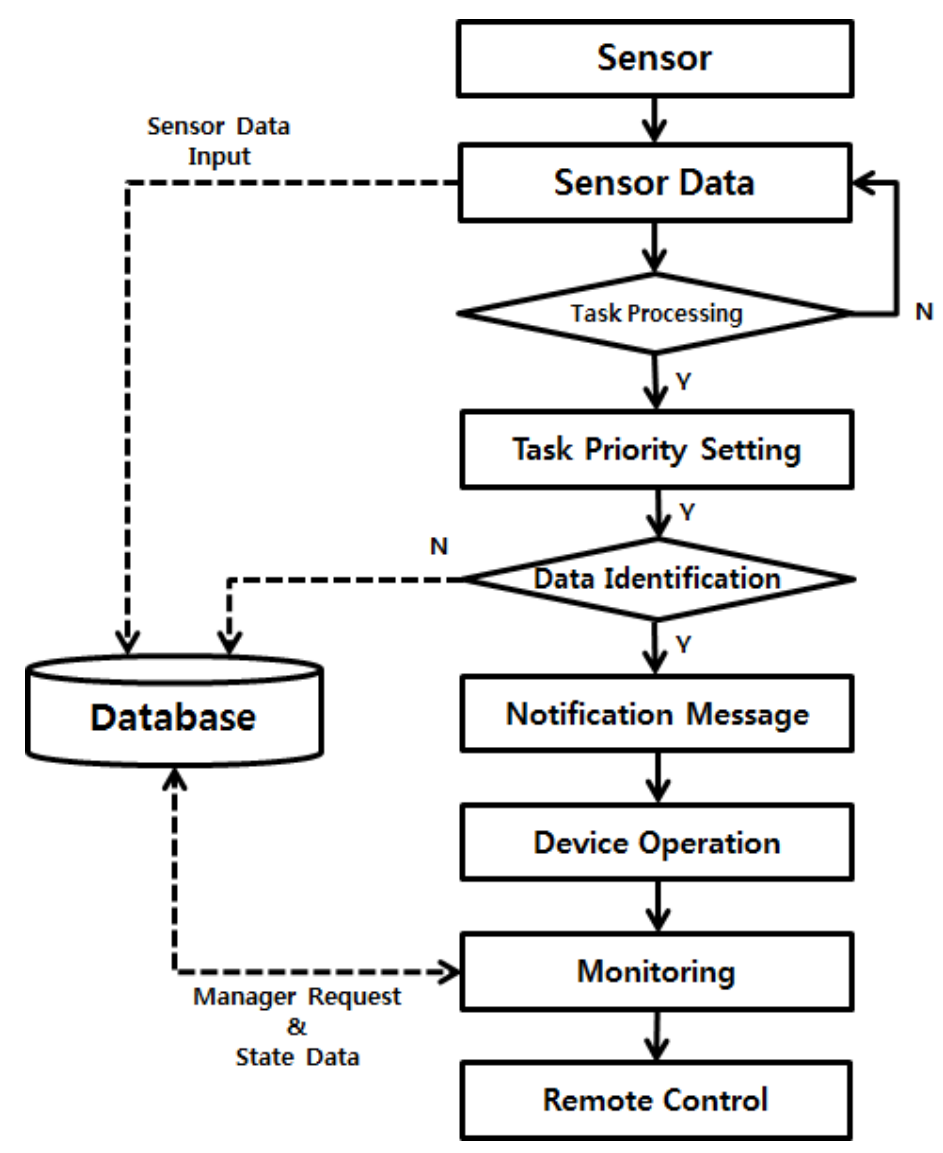

Figure 3. Tasks automatic control algorithm

The measured data from the sensors used for environmental control and crime prevention control is transmitted to the server. The server uses thresholds for ventilation, temperature control, fire, and intrusion to identify work that has occurred. When a job occurs, the system sets the priority among jobs and operates in comparison with the existing job. It identifies whether the task should be processed in real time. When a fire or intrusion that requires real-time processing occurs, a notification message is sent to the administrator, and the operation data is loaded into the database. In addition, necessary devices for the certain job are operated while the system simultaneously receives the notification message. The administrator can monitor and remotely control through the provided alarm message.

Figure 4 shows a scenario for job priorities. Task 1 of the task priority is the fire caused by the temperature and the gas sensor. If the temperature does not exceed the threshold value, and only gas is generated, the window is opened to operate the ventilation operation. If the threshold value of the gas is exceeded, and the threshold value of the temperature is exceeded, the situation is automatically identified as a fire, and a notification message is sent to the administrator. Simultaneously, all devices in operation are stopped. Task 2 is the occurrence of an invasion through vibration and human body sensor. When a door is opened forcibly at a time when the management place system is not in use, vibration is generated, or when the human body detection exceeds the threshold value through the window, the motion identified as an 
intrusion, and a notification message is sent to the administrator. Task 3 is about remote control in the application. When a remote signal is generated by the administrator, the corresponding device is operated. Otherwise, the device operates by an automatic control. Task 4 is the use of management place, which is an unused action by web data. The date and time stored in the database are compared with the current date and time to identify whether or not the management site is used. When the environment control operation is not used, the security control operation is operated instead. Task 5 is the automatic control using temperature, humidity and gas sensor. The sensor data measured in real time are compared with the threshold value of each sensor, and if the value is exceeded, the operation system corresponding to temperature control and ventilation mode occurs. If the threshold value is not exceeded, the management place continues to work.

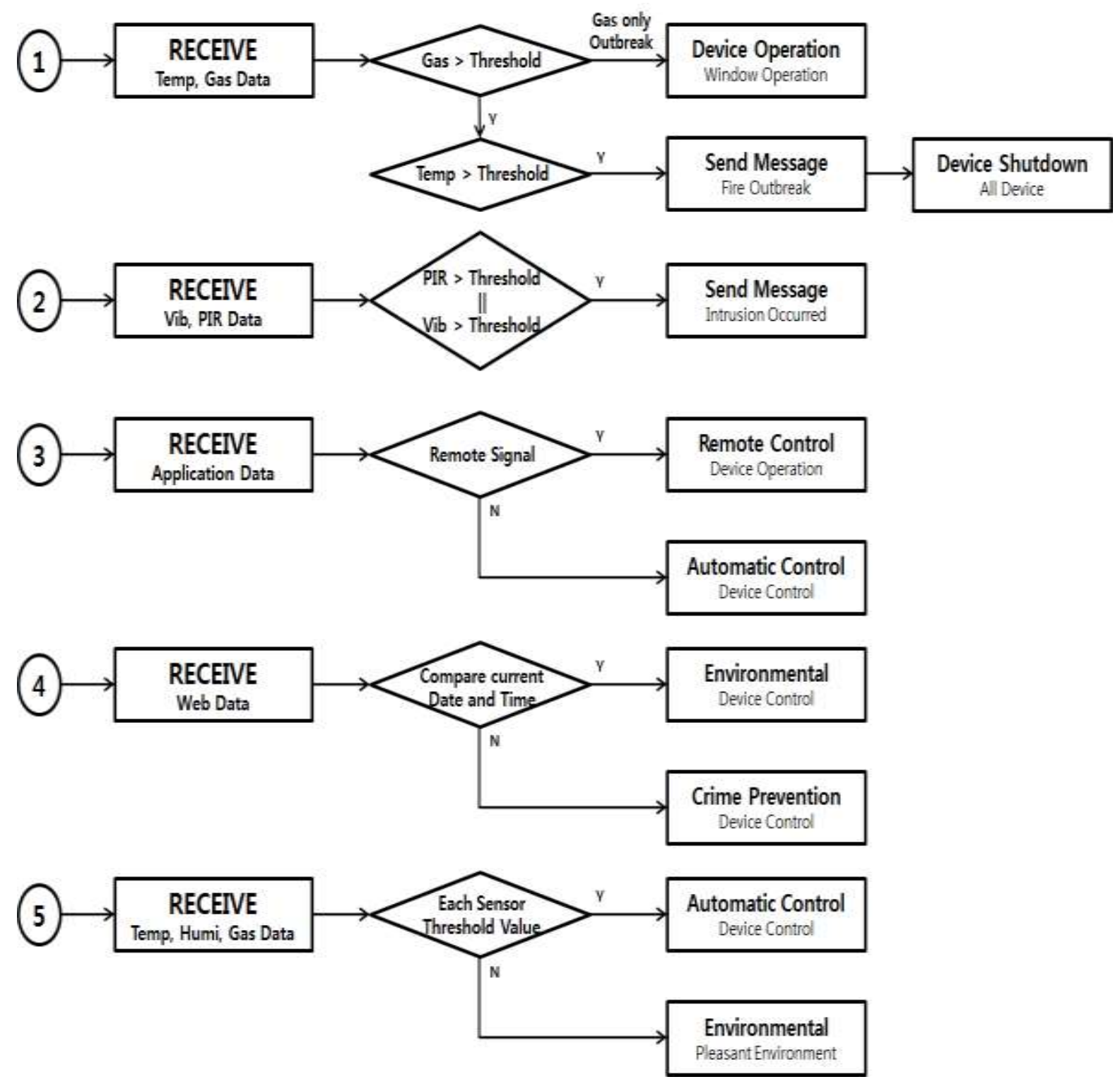

Figure 4. Priority for tasks scenario

\section{SYSTEM IMPLEMENTATION}

This section deals with the implementation of the proposed work automatic control system. The application of the system is an important module for the administrator to monitor and remotely control the sensor data and the status of the device measured in Arduino.

Figure 5 shows the application main page and membership page. If you click the join button on the main page, go to the member registration page, enter the ID, PW, and telephone number of the administrator, 
and click the join button, finally information entered in the database is loaded. When you click the login button, the application compares each information of the administrator loaded in the database and lets you $\log$ in if the information matches. Figure 6 shows the implementation screen to monitor the laboratory status and to control the remote control.

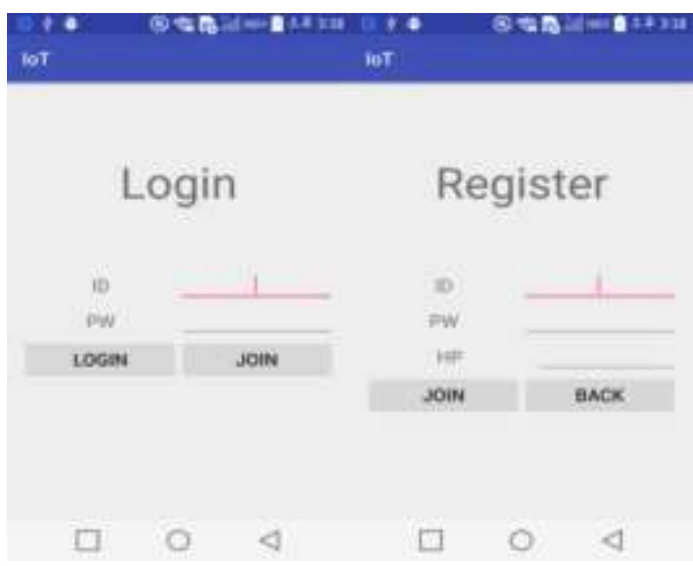

Figure 5. Login \& register page

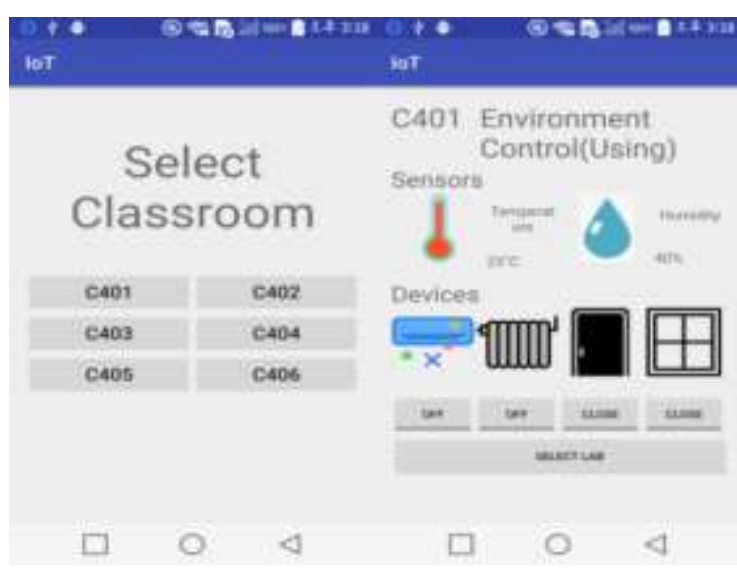

Figure 6. Laboratory selection \& monitoring page

When the administrator logs in, the laboratory to be managed is selected, and the selected laboratory number is stored in the database. This process sends a notification message to the administrator in the management place. The administrator can monitor the number of laboratories that need to be managed, whether they are in use or not, and can check the temperature and humidity measured in real time. You can also remotely control commands for air conditioners, heaters, door locks, and window devices.

Figure 7 shows the danger notification message page. On the left, the administrator's application screen shows a notification message when the management place is not used or when an intrusion occurs during the operation of the security control operation. Notification messages are provided as push pop-up messages through the FCM server in the event of a danger situation. The right page shows a warning message when a fire occurs. In case of fire, system identifies the used time of management place and identifies the 24 hours without separately distinguishing the unused time. In addition, it stops all devices. Figure 8 shows the sensor and device prototype configuration.

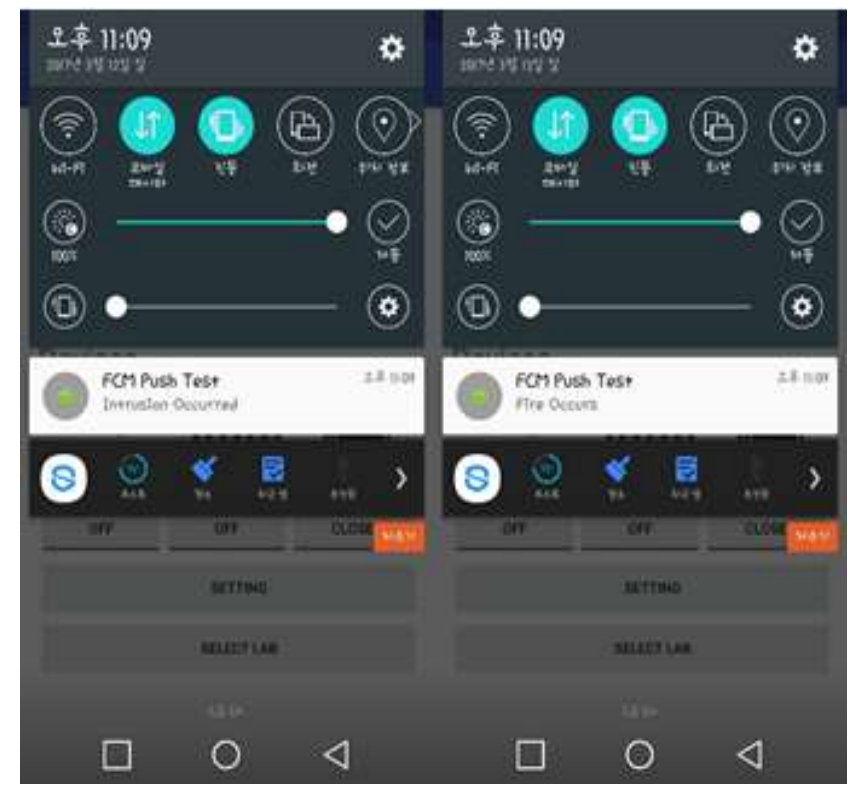

Figure 7. Danger situation notifications page

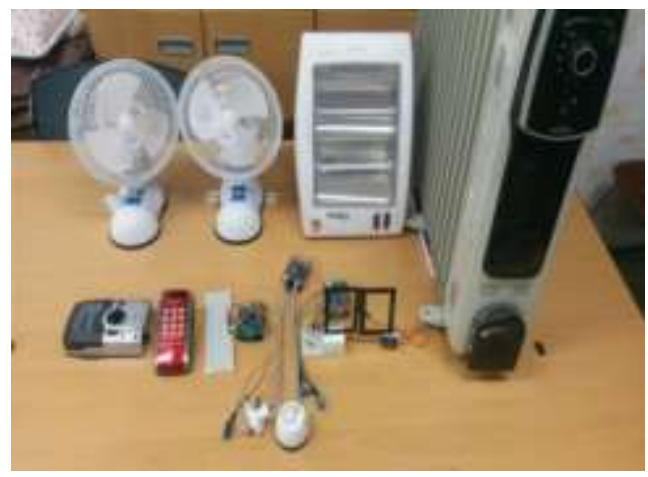

Figure 8. Sensors and device prototype 
The sensors that constitute the prototype of this system are temperature sensor, humidity sensor, gas sensor, vibration sensor, and human body sensor. The device consists of a window, a pen, a heater, and a door lock. The data measured by the sensor is processed in the server through the event-processing conditions, and the corresponding job is loaded into the database. Tasks related to temperature and humidity identify temperature control and fire task, while tasks related to gas identifies fire in conjunction with ventilation and temperature. The vibration and human body sensor identifies the task of forcing a door open or entering through a window. The device connects the SSR to Arduino, which is responsible for environment control and security control, and controls the power by transmitting the $5 \mathrm{~V}$ electric signal of Arduino. SSR can turn on / off the power of the device through power control and operate the device according to the job priority registered in the server.

\section{REVIEW}

In this study, we set the priorities of the tasks that occur in each sensor to solve the problems of other automatic management systems and control the devices to turn on and off by applying the corresponding scenarios. If high priority tasks occur, the system stops the existing tasks. In addition, the accuracy of the fire identification is improved by applying the fusion threshold of the temperature and the gas sensor as the system can accurately identify the fire in the dangerous situation. Table 1 shows the fire identification comparison analysis between the existing fire identification system and the proposed system.

Table 1. System comparative analysis

\begin{tabular}{ccl}
\hline Type & & \multicolumn{1}{c}{ Composition } \\
\hline $\begin{array}{c}\text { Fire identification System } \\
\text { by Temperature }\end{array}$ & $-\begin{array}{l}\text { Slow rise in temperature makes fire identification difficult. } \\
\text { A malfunction may occur if the temperature difference between indoor and } \\
\text { outdoor is large. }\end{array}$ \\
$\begin{array}{c}\text { Fire identification System } \\
\text { by Gas }\end{array}$ & $-\begin{array}{l}\text { Possibility of malfunction in experiments where gas is generated. } \\
\text { Development System }\end{array}$ & - Fire identification by fusion of sensor data. \\
\hline
\end{tabular}

The fire identification system by temperature is classified into the differential type and the constant temperature type. In the case of the differential type, the system operates when the temperature difference per minute is suddenly increased to more than $15^{\circ} \mathrm{C}$. However, there is a problem that when the window opening operation is performed and when the room temperature and the outside temperature are greatly different due to the gradual rise of the temperature, the differential type may experience a sudden rise in temperature and malfunction. The constant temperature method operates when the temperature rises above $70^{\circ} \mathrm{C}$, but since it operates when it reaches a certain temperature, it is difficult to detect the fire early.

The fire identification system by gas is a system that detects smoke caused by a fire and sounds an alarm to respond quickly before a big fire occurs. However, such system has a problem as it wrongly recognizes the generated gas as a fire in a laboratory settings when the gas experiments frequently take place. Figure 9 is a graph showing the device's malfunctions when the temperature suddenly rises due to flame and gas tests.

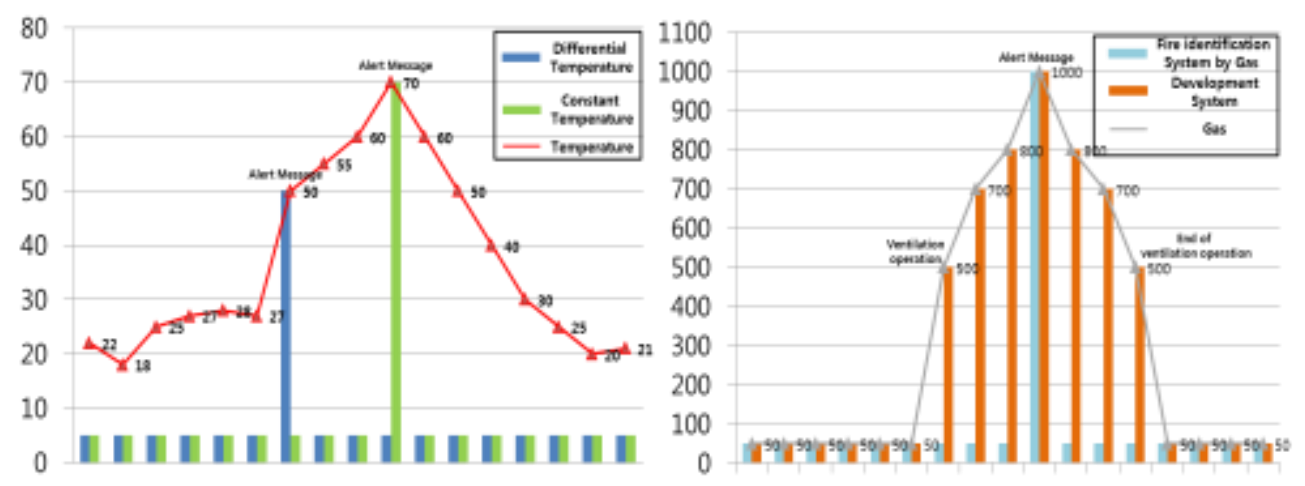

Figure 9. Fire identification system malfunction graph 
In the case of differential fire detection, it was confirmed that a malfunction occurred by transmitting a notification message during a period in which the temperature suddenly rises. In the case of temperaturecontrolled fire detection, when a temperature of $70^{\circ} \mathrm{C}$ or higher is detected, a notification message is sent to confirm malfunction. The gas detector transmits a fire notification message when the gas is measured over 1000 , while the proposed system operates the ventilation operation to reduce the indoor gas when more than 500 gases are detected. When more than 1000 are measured, the fire is identified by comparing with the temperature, so it is possible to identify whether the gas is generated through the experiment.

\section{CONCLUSIONS AND FUTURE WORK AREAS}

Since the existing system handles the data generated by the server in batch, it operates concurrently with the existing work if a certain task that should operate prior to the dangerous situation or the current operation is generated. In this paper, we propose systems that automatically identify the sensor data generated to solve this problem. In this system, the data generated by the sensor is checked in the server through the threshold value to identify whether or not the task should be processed in real time. The identified task sends the command to each of the Arduino via priority setting. Arduino stops the existing operation through the command and then operates the high priority task instead. In addition, web data extraction allows the work to be performed by the date and time of use. The danger situation was identified as fusion data without identifying it as a single sensor data, and a notification message was sent to the manager in case of a dangerous situation. To verify the efficiency of this system, we applied it as a prototype using Arduino and Wi-Fi Shield. This will reduce unnecessary work and waste of power usage. Future research should implement the system proposed in this paper so that the system can be applied to various environments rather than specific spaces and limited situations. This allows users to receive customized services in a more convenient and efficient environment without being restricted by their locations.

\section{ACKNOWLEDGEMENTS}

This research was supported by The Leading Human Resource Training Program of Regional Neo industry through the National Research Foundation of Korea(NRF) funded by the Ministry of Science, ICT and future Planning(No. 2016H1D5A1911091). This work was supported by the research grant of Paichai University in 2020.

\section{REFERENCES}

[1] M. J. Song, "A Study on Business Types of IoT-based Smarthome : Based on the Theory of Platform Typology," The Journal of The Institute of Internet, Broadcasting and Communication, vol. 16, no. 2, pp. 27-40, Apr 2016.

[2] K. Cao, I. Kang, H. CHoi, and H. Jung, "Recent Cabinet Management System Using Dager Priority," Journal of Information and Communication Convergence Engineering, vol. 15, no. 4, pp. 227-231, Dec 2017.

[3] I. C. Areeb, U. Muhammad, and F. Arshad, "Towards the Development of an Efficient and Cost Effective Intelligent Home System Based on the Internet of Things," International Journal of Computer Science and Information Security, vol. 14, no. 6, pp. 343-350, Jun 2016.

[4] W. U. Lee, H. M. Ko, J. H. Yu, and K. B. Sim, "An Implementation of Smart Dormitory System Based on Internet of Things," Journal of Korean Institute of Intelligent Systems, vol. 26, no. 4, pp. 295-300, Aug 2016.

[5] C. K. Dehury, and P. K. Sahoo, "Design and implementation of a novel service management framework for IoT devices in cloud," Journal of Systems and Software, vol. 119, pp. 149-161, Sep 2016.

[6] H. W. Kim, and Y. S. Jeong, "Efficient auto-scaling scheme for rapid storage service using many-core of desktop storage virtualization based on IoT," Neurocomputing, vol. 209, pp. 67-74, Oct. 2016.

[7] K. H. Nam, "A Study on the Office Management Service Platform based on M2M/IoT," The Journal of the Korean institute of electronic communication sciences, vol. 9, no. 12, pp. 1405-1414, 2014.

[8] X. Bing, "Key Internet of Things Technology and Application Research," Applied Mechanics and Materials, vol. 543-547, pp. 3411-3414, Mar 2014.

[9] W. Yonghu, "RFID SpatioTemporal Data Management," TELKOMNIKA Indonesian Journal of Electrical Engineering, vol. 11, no. 3, pp. 1348-1354, Jan 2013.

[10] L. Juntao, "Research of IOTs Complex Event for Supply Chain Application," TELKOMNIKA Indonesian Journal of Electrical Engineering, vol. 11, no. 8, pp. 4296-4305, 2013.

[11] C. S. Kim, H. K. Kim, H. K. Jung, "IoT Distributed Processing System Based on Resource Allocation Algorithm," International Journal of Applied Engineering Research, vol. 12, no. 24, pp. 15050-15054. Jan 2017.

[12] S. Distefano, G. Merlino, A. Puliafito, "A Utility Paradigm for IoT: The Sensing Cloud. Pervasive and mobile computing," vol. 20, pp. 127-114, 2015.

[13] Z. Xuezhi, S. K. Garg, P. Strazdins, P. P. Jayaraman, D. Georgakopoulos, R. Ranjan, "IOTSim: A Simulator for Analysing IoT Applications," Journal of Systems Architecture, vol. 72, pp. 93-107, Jan 2017. 
[14] S. Trilles, A. Calia, O. Belmonte, J. T. Sospedra, R. Montoliu, J. Huerta, "Deployment of an Open Sensorized Platform in a Smart City Context," Future Generation Computer Systems, vol. 76, pp. 221-233, Nov 2017.

[15] T. H. Park, H. J. Seo, B. J. Bae, H. W. Kim, "Secure Message Transmission Against Remote Control System," Journal of Information and Communication Convergence Engineering, vol. 14, no. 4, pp. 233-239, Dec 2016.

[16] K. Cao, H. J. Lee, H. K. Jung, "Task Management System According to Changes in the Situation Based on IoT," Journal of Information Processing System, vol. 13, no. 6, pp. 1459-1466, Dec 2017.

[17] Q. I. Sarhan, N. Abdullah, “Arduino Based Real-Time Home Control System: Design and Implementation,” Journal of University of Duhokorea Information Science Society, vol. 19, no. 1, pp. 133-142, Jan 2016.

[18] J. W. Park, D. S. Kim, N. K. Joo, "Indoor Environment Monitoring and Controlling System design and implementation based on Internet of Things," Journal of the Korea Institute of Information and Communication Engineering, vol. 20, no. 2, pp. 367-374, Feb 2016.

[19] Y. H. Jeon, "A Study on the Security Modeling of Internet of Things(IoT)," Journal of Korean Institute of Information Technology, vol. 15, no. 12, pp. 12-27, Dec 2017.

[20] Y. Evchina, J. Puttonen, A. Dvoryanchikova, J. L. M. Lastra, "Context-aware knowledge-based middleware for selective information delivery in data-intensive monitoring systems," Engineering Applications of Artificial Intelligence, vol. 43, pp. 111-126, Aug 2015.

[21] C. S. Oh, M. S. Seo, J. H. Lee, S. H. Kim, Y. D. Kim, H. J. Park, "Indoor Air Quality Monitoring Systems In The IoT Environment," The Journal of Korean Institute of Communications and Information Sciences, vol. 40, no. 5, pp. 886-891, May 2015.

[22] C. Perera, A. V. Vasilakos, “A Knowledge-based resource discovery for Internet of Things," KnowledgeBased Systems, vol. 109, pp. 122-136, Oct 2016.

[23] S. L. Choi, S. J. Koh, "Distributed CoAP Handover Using Distributed Mobility Agents in Internet-of Things Networks," Journal of Information and Communication Convergence Engineering, vol. 15, no. 1, pp. 37-42, Mar 2017.

[24] K. M. Jang, D. H. Jeong, H. K. Jung, "User Task Management System based on Device Priority," Journal of the Korea Institute of Information and Communication Engineering, vol. 21, no. 3, pp. 657-662, Mar 2017.

[25] M. Imdad, D. W. Jacob, H. Mahdin, Z. Baharum, S. M. Shaharudin, M. S. AzmiM, "Internet of things: security requirements, attacks and counter measures," Indonesian Journal of Electrical Engineering and Computer Science, vol. 18, no. 3, pp. 1520-1530, Jun 2020.

[26] C. R Srinivasan, Guru Charan, P. C. S. Babu, "An IoT based SMART patient health monitoring system," Indonesian Journal of Electrical Engineering and Computer Science, vol. 18, no. 3, pp. 1657-1664, Jun 2020.

[27] E. M. M. Yusof, M. I. Yusof, R. Ali, I. H. Harjimi, Q. K. Bahrin, "Welding station monitoring system using internet of thing (IoT)," Indonesian Journal of Electrical Engineering and Computer Science, vol. 18, no. 3, pp. 1319-1330, Jun 2020.

\section{BIOGRAPHIES OF AUTHORS}

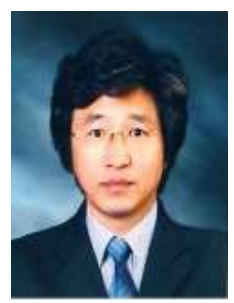

Hankil Kim received the B.S., M.S. degrees from the Department of Electronic Engineering of Hanbat National University, Korea, in 2006, and 2011, and the Ph. D. degree in 2015 from the Department of Computer Engineering of Paichai University, Korea. Since 2006, he has worked in the Department of Music \& Sound Technology at Korea University of Media Arts as a professor. His current research interests include multimedia sound, broadcast sound, SR(Sound Reinforcement), Sound Engineering, and database.

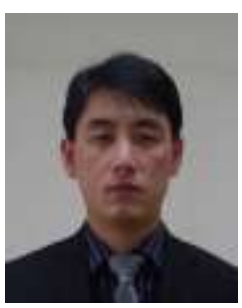

Jaehyun Park received the B.S. degree in 1995 from the Department of Electronic Engineering of Wonkwang University and M.S. degree in 2006 from the Department of Information and Communication Engineering of Chungmnam National University, Korea. Since 1995, he has worked at K-water(Korea Water Resource Corporation) where he now works as a Senior Manager. His current research interests include multimedia document architecture modeling, bigdata, IoT and AI.

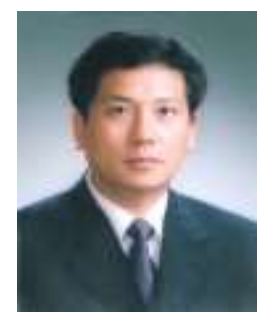

Hoekyung Jung received the B.S degree in 1987 and Ph. D. degree in 1993 from the Department of Computer Engineering of Kwangwoon University, Korea. From 1994 to 1995, he worked for ETRI as a researcher. Since 1994, he has worked in the department of Computer Engineering at Paichai University, where he now works as a professor. His current research interests include multimedia document architecture modeling, machine learning, IoT, bigdata, and artificial intelligence. 